Mots. Les langages du politique

\title{
Une étymologie émotionnelle : assassins
}

\section{Maurice Tournier}

\section{Q OpenEdition}

\section{Journals}

Édition électronique

URL : https://journals.openedition.org/mots/5023

DOI : $10.4000 /$ mots.5023

ISSN : 1960-6001

\section{Éditeur}

ENS Éditions

\section{Édition imprimée}

Date de publication : 1 mars 2004

Pagination : 147-149

ISBN : 2-84788-056-9

ISSN : 0243-6450

\section{Référence électronique}

Maurice Tournier, "Une étymologie émotionnelle : assassins », Mots. Les langages du politique [En ligne], 74 | 2004, mis en ligne le 24 avril 2008, consulté le 23 avril 2022. URL : http:// journals.openedition.org/mots/5023; DOI : https://doi.org/10.4000/mots.5023 
Maurice TOURNIER

\section{Des mots en politique}

\section{Une étymologie émotionnelle: assassins}

Il fut un temps où les assassins étaient drogués au hachisch et, rêvant d'accéder au jardin des délices, se ruaient sur les voyageurs pour les trucider au nom d'Allah. C'est en tous cas ce que racontent nos dictionnaires étymologiques. Ils reproduisent en cela les terreurs et les préjugés des pélerins et des croisés décimés en Syrie dans des embuscades sans pardon. Il est certes possible (mais non prouvé) que les sectaires du Vieux de la montagne, sheikh el djebel d'Alamut, se dotent, en avalant leur potion, d'un courage meurtrier et suicidaire. Mais est-ce suffisant pour que le terme trouve là sa source initiale?

Nous avions évoqué, dans une chronique de Mots déjà ancienne ${ }^{1}$, une double hypothèse sur les origines d'assassin. Il apparait de plus en plus évident, des textes d'Alamut ayant refait surface, qu'une origine arabe du mot est historiquement première. Il s'agit du terme-racine «Assas », Asl, Usûl, c'est-àdire «base, source, principes, fondements» de la foi islamique ${ }^{2}$. Les Assassiyoun étaient des fondamentalistes religieux, les «vrais croyants» qui défendaient leur foi en attaquant les intrus jusqu'à mourir pour tuer. Foi en Allah mais aussi en Ismaïl, ce septième et dernier des prophètes que ces dissidents chiites reconnaissaient dans l'imam qui avait sur eux une autorité absolue ${ }^{3}$.

Sur cette source primordiale est venue, dans la mentalité des pélerins et des croisés, se superposer leur émotion de victimes, avec la vision, évidente pour eux, de kamikazes artificiellement fanatisés. Massacrés par les moines bédouins fondant sur eux de leur forteresse imprenable de l'Elbourz, ces

1. Voir «Petite histoire des verbes qui donnent la mort», Mots, $\mathrm{n}^{\circ} 24$, septembre 1990 , p. $92-93$.

2. Mohammed Arkoun, Penser l'islam aujourd'hui, Alger, Laphomic/ENAL, 1993, p. 171.

3. «À ce culte de l'autorité se rattache le devoir de l'obéissance absolue envers les supérieurs qui, particulièrement chez les Assassins, ce rameau du mouvement ismaïlien, apparait sous la forme d'un véritable terrorisme» (I. Goldziher, Le dogme et la foi de l'Islam, Paris, Librairie orientaliste Paul Geuthner, 1958, p. 207. 
«mécréants » auraient, pour ainsi dire, recréé le terme en français en relatant les méfaits d'Hachischiyoun devenus légendaires. Mais pourquoi écrivaient-ils leur nom le plus souvent, comme les Italiens à la même époque, sans $H$ initial et surtout sans $c h$ interne? Pour respecter la phonation entendue. Le sénéchal de Joinville (Vie de Saint Louis, 13 ${ }^{\mathrm{e}}$ siècle) parle ainsi de la secte d'Alamut en orthographiant Assacis (italien Assassini). Ce mot d'assassin, écho d'Assassiyoun, a pris ainsi en charge connotative et sémantique l'effroi et la détestation propres aux pélerins et croisés, mais sans d'abord en tordre la prononciation pour la rapprocher du hachisch. Cette seconde étymologie ne devient explicite que chez Marco Polo. C'est son récit, fait sur des on-dit, qui a rajouté la drogue au fanatisme.

Le Vieux était appelé en leur langage Alaeddin et, avec tout le peuple qu'il commandait, était un fidèle de la loi de Mahomet. Si rêvait-il d'une méchanceté inouie, assavoir comment il tournerait de ses hommes en audacieux meurtriers ou spadassins, de ceux qu'on nomme communément assassins.

Le mot hachisch n'arrive pourtant pas sous sa plume. Marco Polo ne parle que d'un breuvage qui ferait entrevoir (en rêve ou, comme l'assure notre conteur, dans la réalité des fleurs, fruits, vins, miels et femmes des jardins d'Alamut) le Paradis, auquel l'assassin est convié, son contrat rempli.

Il leur faisait donner breuvage à boire, par l'effet de quoi ils tombaient endormis aussitôt. [...] Au bout de quatre à cinq jours, quand le Vieux veut en envoyer un en quelque lieu pour occire un homme, alors il fait derechef donner le breuvage à autant de jeunes gens qu'il veut. [...] Ils se comportent très humblement et s'agenouillent en gens qui le croient un grand prophète. [...] Par ce moyen, il a tant inspiré à son peuple le désir de mourir pour aller en Paradis, que celui à qui le Vieux ordonne d'aller mourir en son nom, il se juge bienheureux, ayant la certitude d'aller en Paradis ${ }^{4}$.

Ce fanatisme a dû émouvoir et effrayer à tel point les intrus occidentaux que nos dictionnaires étymologiques reproduisent encore, à propos d'assassins, l'étymon populaire d'Hachischiyoun, buveurs ou fumeurs de hachisch, ces fous d'Allah ne pouvant être, pour l'Occident chrétien, que des drogués inconscients ${ }^{5}$. Remarquons qu'un tel étymon est totalement absent du récit de

4. Marco Polo, Le devisement du monde. Le livre des merveilles (fin du $13^{\mathrm{e}}$ siècle), Paris, La Découverte, 1998, tome 1, p. 113-115 (trad. Hambis, 1955).

5. «Assassin (16 $\mathrm{s}$.), empr. d'abord au sens de "tueur à gages" puis de "meurtrier avec préméditation" à l'italien assasino, de l'arabe hassasin, plur. de hassas, au sens de "fumeur de hachisch", nom donné au M. Â. par leurs ennemis aux ismaéliens de Syrie, cet ordre religieux ayant été responsable de nombreux assassinats de chrétiens comme de musulmans » (E. Baumgartner, Ph. Ménard, Dictionnaire étymologique et historique de la langue française, Paris, Livre de Poche, LGF, 1996, p. 51). 
Joinville, selon qui l'«assassin» est celui qui se fait tuer pour tuer, qui recherche la mort de l'autre dans sa propre mort, bref le kamikaze mystique:

Les Bédouins ne croient point en Mahomet mais croient en la loi d'Ali, qui fut oncle de Mahomet, et aussi en le Vieus de la Montagne, cil qui nourrit les Assacis. Ils croient que, quand ils meurent pour leur seigneur ou en bonne intention, leur âme trouve un meilleur corps, bien plus heureux. Pour cela, les Assacis ne se soucient pas d'être tués quand ils obéissent au Vieil de la Montaigne. [...] Leur croyance est que nul ne peut mourir qu'à son jour [...]. En bataille, ils ne portent rien que l'épée et le glaive» et, bien sûr, ajoute le blond Joinville, «chevel et barbes tuit noir ${ }^{6}$.

C'est bien Marco Polo qui a décrit ces fondamentalistes en fous drogués ${ }^{7}$, histoire reprise, dit-on, par l'orientaliste Sylvestre de Sacy pour argent comptant et diffusée jusqu'à nos jours, ne serait-ce que par le Baudelaire des Paradis artificiels. Voilà donc un mot double, à double naissance, d'une part témoin arabe et islamique dans son écriture et sa référence première («fondamentalistes»), d'autre part témoin mental de l'Occident dans sa signification française («tueurs») et son évaluation négative, de type émotionnel, laquelle a pris le pas sur l'origine religieuse orientale à un point tel que s'est imposée comme explication savante, voire certaine, réaffirmée de dictionnaire en dictionnaire, une étymologie populaire totalement absente du mot à son départ. Parfait exemple d'étymologie "plurielle», dont la valeur originelle (mystique et laudative) a cédé la place en français à un greffon de sens mais non de forme (polémique et péjoratif). "Vérité en deçà des Pyrénées, erreur au-delà.»

6. Jean de Joinville, La vie de saint Louis (1272-1309), texte original dans Extraits des chroniqueurs français, Paris, Hachette, $12^{\mathrm{e}}$ éd., 1927, p. 147-149.

7. La description des Assassins que donne Marco Polo (voir le spectacle des jardins d'Alamut) et celle du sire de Joinville (des gens couverts de peaux de bêtes) sont très différentes. On sait qu'il faut se méfier de certains témoignages de Marco Polo, qui n'a pas vu tout ce qu'il décrit (hommes sans tête ou à tête de chien, par exemple). 